

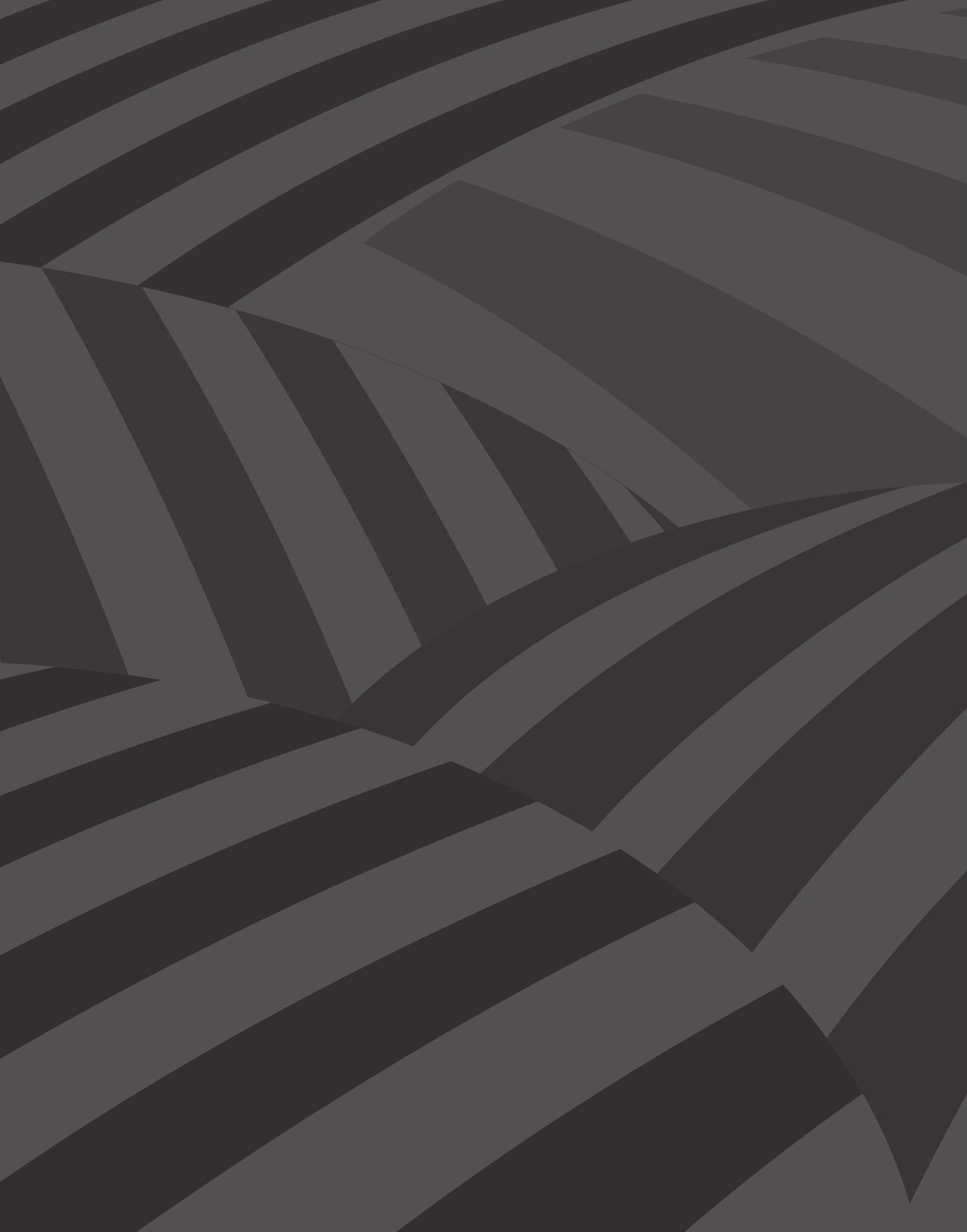




\section{Narrativas territoriales Embera entre el Alto San Juan y Magdalena Medio}

Por Juan Manuel Díaz*

Resumen: el artículo aborda cómo se percibe, interpreta y experimenta el destierro y el desarraigo derivado del conflicto armado, en dos comunidades Embera asentadas en el municipio de Puerto Boyacá, mediante un enfoque narrativo y territorial. En él se describen las principales características socio-políticas del pueblo Embera y la crisis humanitaria, mediante un enfoque cualitativo que se nutre de las historias de vida sobre el destierro y el desarraigo en la cuenca alta del río San Juan. Así mismo, revela los sentidos, tensiones y relaciones de poder que desarrollan las comunidades Embera en Puerto Boyacá, mediante una perspectiva cualitativa donde presenta un conjunto de continuidades y rupturas que revelan cómo opera la territorialidad Embera en escenarios de violencia y marginalización. Finalmente, ofrece herramientas teórico-metodológicas para analizar el destierro y el desarraigo como parte de procesos de territorialización que contienen prácticas y discursos asociados a la producción social de territorios y narrativas.

Palabras clave: Embera, destierro, desarraigo, territorialización, narrativa territorial, territorialidad humana.

\section{Embera Territorial Narratives Between the High San Juan and Magdalena Medio}

Abstract: the article addresses how the banishment and uprooting derived from the armed conflict over two Embera communities settled in the municipality of Puerto Boyacá is perceived, interpreted and experienced through a narrative and territorial approach. The document describes the main socio-political characteristics of the Embera people and the humanitarian crisis through a qualitative approach that draws on life stories about the banishment and uprooting of the Upper San Juan river basin. The article reveals the senses, tensions and power relations that the Embera communities develop in Puerto Boyacá, through a qualitative perspective that presents a set of continuities, and ruptures that reveal how or Embera territoriality operates in scenarios of violence and marginalization. Finally, the article offers theoretical-methodological tools to analyze exile and

* Antropólogo de la Pontificia Universidad Javeriana, sede Bogotá; candidato a magíster en Geografía por la Universidad Nacional de Colombia, con el proyecto "Producción de comunidades y territorios ambivalentes. Entre el reconocimiento y la repulsión de las familias Embera asentadas en Puerto Boyacá, Colombia”. Orcid: 0000-0002-6460-3658. Correo electrónico: judiazs@unal.edu.co 
uprooting as part of territorialization processes that involve practices and discourses associated with the social production of territories and narratives.

Keywords: Embera, banishment, uprooting, territorialization, territorial narrative, human territoriality.

Cómo citar este artículo: Díaz, Juan Manuel (2020). Narrativas territoriales Embera entre el Alto San Juan y Magdalena Medio. Revista Controversia, 214, 167-208.

Fecha de recepción: 1 de octubre de 2019

Fecha de aprobación: 3 de febrero de 2020

\section{Introducción}

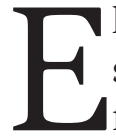

1 conflicto armado en Colombia ha transformado las dinámicas sociales y territoriales de las comunidades Embera. Según las cifras de las organizaciones indígenas, entre los años 1985-2012 han sido expulsados 36.199 Embera; esto representa el 30\% de una población de 181.405 personas hoy en día distribuidas en 17 departamentos y 124 municipios del país (OREWA, 2013). Según la Consultoría para los Derechos Humanos y el Desplazamiento codHEs (2014), durante el destierro las familias Embera son expulsadas a ciudades capitales e intermedias donde experimentan procesos de exclusión que las obliga a instalarse en lugares marginales, sin poder articularse con las cadenas comerciales y las dinámicas de los escenarios urbanos. Asimismo, se deteriora su vínculo con el territorio, su autonomía alimentaria y productiva, se transforman los roles de género y son objeto de prácticas de estigmatización y racismo. A pesar de la oferta institucional de carácter jurídico y territorial que se ha desarrollado en el marco de la Ley de víctimas y restitución de tierras (Ley 1448 de 2011, Decreto 4633 de 2011), las sentencias y órdenes en el sentido de restablecer derechos de las comunidades Embera, emitidas por la Corte Constitucional ${ }^{1}$ y las

1 Sentencia T-737 de 2017 sobre el derecho a la propiedad colectiva de la comunidad Embera Katío (Puerto Boyacá, Boyacá). 
salas especializadas de Restitución de Tierras²; el Acuerdo de Paz entre el Estado y la guerrilla Fuerzas Armadas Revolucionarias de Colombia (FARC), aún se mantiene la marginalización, la violencia y el desplazamiento forzado del pueblo Embera.

Uno de los municipios donde hay asentamientos Embera derivados del conflicto armado es Puerto Boyacá, conocido históricamente como la capital antisubversiva de Colombia y uno de los municipios donde opera la industria de hidrocarburos desde las primeras décadas del siglo xx. Durante la década de 1980 se formaron grupos paramilitares que recibieron apoyo logístico del Ejército Nacional, el gremio ganadero y el narcotráfico, con el objetivo de iniciar una guerra antisubversiva que arremetió contra el Frente 4 de las FARC, la economía campesina, la tenencia de tierra y líderes políticos de izquierda (Medina, 1990). Durante la década de 1990 se organizó una estructura regional paramilitar que se nutría de los grupos de Puerto Boyacá, el recio control a la población, la organización del territorio, el dominio de la industria de hidrocarburos, el narcotráfico, la ganadería, el crecimiento urbano y una economía campesina en deterioro. Durante la década del 2000 los paramilitares de Puerto Boyacá controlaron y administraron cultivos de uso ilícito en la serranía de Las Quinchas, ${ }^{3}$ en ese entonces Puerto Boyacá junto con el municipio vecino

2 Tribunal Superior, Distrito Judicial de Antioquia, Sentencia 007 de 2014 referente a la restitución de derechos territoriales del Resguardo Tahami del Alto Andagueda (Bagadó, Chocó). Juzgado Primero Civil del Circuito Especializado en Restitución de Tierras de Quibdó. Sentencia 052 de 2017 de restitución de derechos territoriales del resguardo Mondo-mondocito (Tado, Chocó).

3 La serranía de Las Quinchas es un Parque Natural Regional declarado como tal en el año 2008. Está ubicado entre los 300 y 1.500 msnm. La serranía se constituyó como área de reserva forestal en el año 2008, con un área de 21.226 (ha) entre los municipios de Otanche y Puerto Boyacá. En Puerto Boyacá el área del parque y de uso exclusivo de reserva forestal es de aproximadamente 15.000 (ha), con 8.000 (ha) de zona de amortiguación y 4.000 (ha) de zona de influencia. El conjunto de áreas suman 27.000 (ha) que corresponden al 18,37\% del área municipal (Katz, 2019). Allí nacen los ríos Ermitaño y Velásquez, así como docenas de quebradas que desembocan en el río Guaguaquí y luego en el río Magdalena . En sus laderas están ubicados predios de entre 20-80 (ha) que concentran la producción agrícolacampesina del municipio. 
de Otanche concentraron el 90,4\% de hectáreas cultivadas con coca en el departamento de Boyacá entre el 2000-2011 (Katz, 2019).

En el año 2002 se reconoce una parcialidad y cabildo Embera ChamíKatío en el municipio de Puerto Boyacá (MinInterior, 2004). La población se caracteriza como víctima del conflicto armado en condición de desplazamiento forzado de la cuenca alta del río San Juan (entre los límites de los departamentos del Chocó y Risaralda). El reconocimiento derivó en acciones institucionales para contrarrestar la situación de pérdida de cultura y "hacinamiento en viviendas en madera y plástico, en condiciones de extrema pobreza, niños menores de cinco años que sufren enfermedades cutáneas, fiebres, inflamaciones, desnutrición y no cuentan con ninguna atención en salud" (MinInterior, 2004). La atención facilitó su reubicación transitoria en un predio rural de 57 hectáreas. Para el año 2005 Puerto Boyacá contaba con 285 emberas distribuidos en 37 familias, según el censo nacional del mismo año. ${ }^{4}$

La reubicación de la parcialidad indígena permitió que se formara la comunidad Motordochake alto nacabera dua que se traduce como "tierra nuestra de quebradas de piedra blanca [en honor al mayor] Nacabera" (en adelante Motordochake). Durante el proceso, los miembros de la comunidad se rearticularon con las dinámicas de Puerto Boyacá bajo un modelo colectivo que transformó las experiencias de desarraigo e inauguró nuevas relaciones a nivel territorial. No obstante, la reubicación fue una medida transitoria, porque se adquiere bajo la figura jurídica de comodato, un contrato de uso y préstamo de un inmueble que no deriva en la titularidad de este.

4 Del conjunto de la población censada el 44,3\% (126 personas) había nacido en Puerto Boyacá y el 24\% (68 personas) no tenía más de cinco años en Puerto Boyacá. El 14\% (41 personas) estaba inscrito en programas educativos y el 18\% (52 personas) sabían leer y escribir. 
En el presente documento se analiza cómo las familias Embera Chamí Y Katío de Puerto Boyacá, distribuidas hoy en día en dos comunidades, perciben, interpretan y experimentan el destierro y el desarraigo. Dicho análisis se hace mediante un enfoque narrativo circunscrito al discurso y prácticas territoriales que proporcionan aportes sobre los procesos de producción territorial que generan los indígenas en zonas rurales y urbanas fuera de sus resguardos de origen. El argumento es mostrar cómo las representaciones del Magdalena Medio por parte de los mayores Embera permitió cimentar una idea de prosperidad y de abundancia de tierras, que posibilitó construir un circuito territorial que sirvió como recurso para enfrentar el padecimiento simbólico y físico derivado de la violencia en el Alto San Juan. No obstante, más que corroborar la relación entre regiones, interesa entender cómo se narran las experiencias del pasado antes del conflicto armado y analizar su correlación o continuidad con las dinámicas de destierro, desarraigo y territorialización contemporáneas.

El artículo presenta el resultado de la investigación "Producción de comunidades y territorios ambivalentes. Entre el reconocimiento y la repulsión de las familias Embera asentadas en Puerto Boyacá, Colombia”, adelantada para optar por el título de magíster en Geografía por la Universidad Nacional de Colombia. El proyecto fue financiado por la beca de investigación Orlando Fals Borda 2018, de la Facultad de Ciencias Humanas, y contó con un trabajo de campo de cuatro meses (marzo, abril, mayo y agosto del 2019) en el municipio de Puerto Boyacá. El trabajo de campo fue de corte etnográfico, compuesto por un proceso de observación participante en las dos comunidades donde se registraron historias de vida, líneas de tiempo y cartografías sociales de manera participativa sobre diversas temáticas. La participación se apoyó con dos asistentes de investigación, jóvenes letrados de cada comunidad, que iniciaron la recolección de relatos y memorias sobre el destierro, el desarraigo y la territorialización entre la cuenca alta del río San Juan y Puerto Boyacá. Los datos suministrados por cada asistente permitieron elaborar una estructura narrativa provisional, que se fue ampliando du- 
rante las conversaciones y encuentros que se realizaban al compartir una comida, socola, siembra o una recolección de leña.

El documento se divide en seis apartados. En el primero se realiza una breve introducción de las comunidades Embera del Alto San Juan. En el segundo se presenta el concepto de territorialidad y su relación con las narrativas territoriales. El tercer apartado expone y analiza un conjunto de narraciones producidas por las comunidades Embera acerca de los procesos de destierro, desarraigo y territorialización que generan sentidos de horror y refugio entre el Alto San Juan y Puerto Boyacá. En la cuarta sección se analizan los procesos de producción espacial en Puerto Boyacá y las experiencias, prácticas y representaciones asociadas a las dinámicas de territorialización. Seguidamente, en el quinto título se ofrece un análisis de los conflictos territoriales internos de las comunidades Embera derivados de las prácticas espaciales institucionales y su repercusión en las dinámicas territoriales de Puerto Boyacá. Finalmente, se aborda la pertinencia de comprender el destierro y el desarraigo como parte de procesos de territorialización que involucran prácticas y discursos asociados a la producción social de territorios y narrativas.

\section{Sobre el pueblo Embera, el Alto San Juan y el conflicto armado}

El pueblo Embera es una de los grupos indígenas con más extensión territorial en Colombia. Su presencia se extiende hasta el litoral pacífico en Ecuador y Panamá. Según el antropólogo Mauricio Pardo (1987, pp. 49-50) hay cinco grandes áreas fonológicas y dialectales en el pueblo Embera: a) la cuenca alta del río San Juan y Andágueda (Chocó, Risaralda); b) la cuenca alta del río Atrato, río Bojayá y Darién Panameño (Chocó y Panamá ); c) la cuenca alta del río San Jorge y Sinú (Noroeste antioqueño y Córdoba); d) la cuenca media del río Baudó (Chocó); y e) el sur del litoral pacífico colombiano en los ríos Saija (Cauca), Satinga y Saquianga (Nariño). A pesar de los matices, diversos autores trazan una división sociocultural del pueblo Embera según el marco geográfico 
que habitan. Por un lado, están los Embera de río (Embera dobidá) de la selva tropical del pacífico, y por otro los Embera de montaña (Embera eyabida) de la selva subandina en las estribaciones y ramales de la cordillera Occidental, y los Embera eperara del sur del litoral pacífico (Pardo, 1983; Ulloa, 1992).

Pese a la diversidad, los estudios etnológicos reconocen una unidad sociocultural entre el pueblo Embera, caracterizado por un asentamiento móvil y disperso basado en la autonomía familiar. Su unidad social es la parentela, que se elabora sobre un hombre adulto que sirve como punto de pertenencia consanguínea entre abuelos, nietos y primos de primera línea (Stipek, 1976). De acuerdo con Pardo (1983), se trata de un pueblo exógamo, ligado entre sí por una extensa red de intercambios matrimoniales en que "la condición para escoger un cónyuge es que esté situado más allá de dos grados de consanguineidad (nota 7, p. 613).

Generalmente durante los primeros meses de matrimonio se vive en el tambo [casa] de uno de los suegros. Con el nacimiento de los hijos puede recibir tierra con cualquiera de las dos familias y construir una nueva casa en ocasiones el nuevo matrimonio migra a otra localidad (Nota 8, p. 614).

La residencia de la parentela no es unilocal, es decir, el conjunto de parientes puede estar distribuido en diferentes localidades (Pardo, 1983) y su relación genera dinámicas de circulación de personas, bienes y representaciones, lo que en el presente texto se denomina circuito territorial Embera.

Por otra parte, la organización social Embera es de carácter segmentario, es decir, "ante el crecimiento de la población y el agotamiento de los recursos disponibles en su territorio, o a causa de los conflictos internos, se desprenden grupos de tamaño diverso en búsqueda de un nuevo lugar para vivir" (Vasco, 2011 p. 7). Según Stipek (1976), cuando la parentela crece y se extiende, las personas construyen unidades independientes que sobrepasan las capacidades agrícolas de los suelos, produciendo es- 
cenarios de escasez que se interpretan con acusaciones y hostilidad que pueden desatar conflictos, cuyo resultado pueden ser homicidios, abandono del territorio y segmentaciones de una comunidad.

En lo que respecta a las comunidades CHAmí y Katío de Puerto Boyacá, sus miembros provienen de la cuenca alta del río San Juan, por lo cual son comunidades eyabida. Se caracterizan por habitar pequeñas quebradas, en su mayoría no navegables, manejar una agricultura itinerante y caza trashumante. El alto San Juan recoge las aguas que discurren de la vertiente oeste de la cordillera Occidental, a la altura del noreste del departamento de Risaralda y suroeste de Antioquia, entre los 1.000$2.000 \mathrm{msnm}$. En Risaralda el río recorre los municipios de Mistrató y Pueblo Rico, "50 kilómetros y aproximadamente 1.165 km2 (el 29\% de la extensión del departamento)” (Vasco, 1975). Los principales afluentes del San Juan en Risaralda son: el río Agüita (Mistrató) y el río Tatamá (Pueblo Rico). El principal centro poblado es el corregimiento de Santa Cecilia, ubicado en el municipio de Pueblo Rico, y sobre el área se constituyeron dos resguardos —Unificado de Chami y Gito Docabúy dos figuras de conservación —el Parque Natural Nacional Tatamá y el Distrito de Manejo Integrado de la Cuchilla del San Juan- (Figura 1).

La cuenca alta finaliza en el municipio de Tadó (Chocó) con una pendiente entre los 400-600 msnm. El ecosistema que predomina en este sector es de bosque pluvial tropical y bosque húmedo tropical, donde sobresalen "relieves ligeramente ondulado, montañoso y valles planos formados por las cuencas naturales de sus ríos” (Mosquera, 2011, p. 34). En la extensión chochoca los principales ríos que desembocan en el río San Juan son: Guarato, Lloraudó, Condoto, Tarena, Mondó y Bochoromá. En esa área hay cinco resguardos sobre los ríos que desembocan al San Juan: Silencio, Bochoroma, Mondó-mondocito, Tarena y Peñas del Olvido, que coexisten con las tierras colectivas del Consejo Comunitario Mayor del Alto San Juan (ASOCASAN). 
Figura 1. Alto San Juan. Elaboración propia. GWS 84.

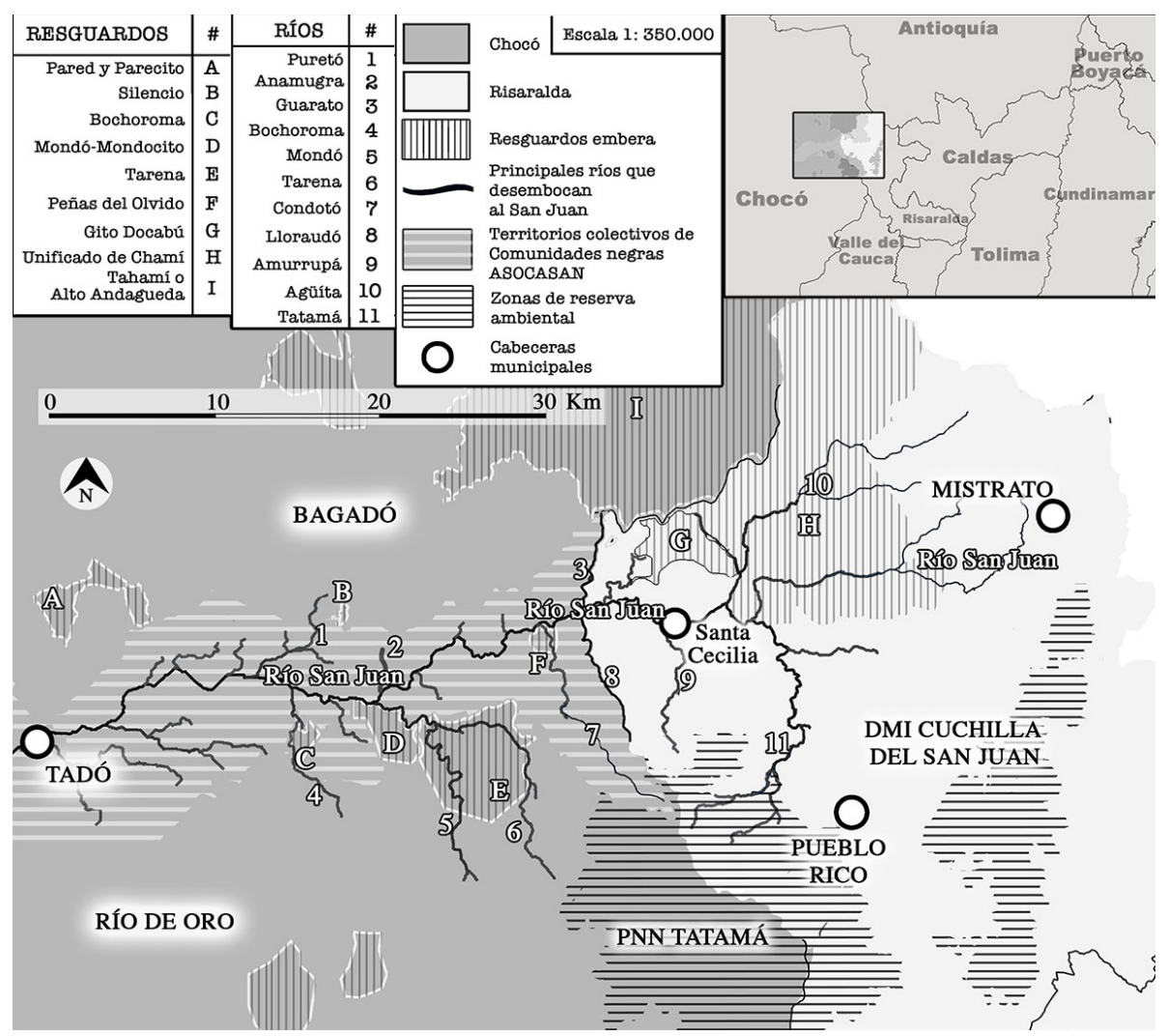

Fuente: Elaboración propia. GWS 84. Observatorio de Territorios Étnicos de la Universidad Javeriana y cartografías sociales del trabajo de campo.

Desde 1992 la principal vía de acceso conecta a Quibdó con Pereira, transita en el municipio de Pueblo Rico y bordea el río San Juan desde el corregimiento de Santa Cecilia con destino a Tadó. A pesar de que se señaló que los grupos indígenas que habitan el Alto San Juan son eyabida, las poblaciones se autodefinen como Embera Chamí y Embera Katío. La población Chamí ocupa el Resguardo Unificado de Chamí y los demás resguardos son de pertenencia Katío. 
El territorio Embera del Alto San Juan es una región estratégica militarmente, por ser una de las rutas de acceso al Pacífico desde el eje cafetero; esta característica facilitó el ingreso de los grupos armados desde la década de 1980. Primero ingresa la guerrilla del M-19, le siguen las FARC, el ELN y su disidencia: el Ejército Revolucionario Guevarista (ERG). En el año 2000 ingresan el Bloque Metro y el Frente Héroes del Chocó de las Autodefensas Unidas de Colombia en los municipios de Carmen de Atrato y Tadó. La incursión paramilitar en el Alto San Juan instala retenes permanentes sobre la vía Santa Cecilia-Tadó, destruyen puentes entre las comunidades indígenas, incineran viviendas e incrementa el desplazamiento forzado (Juzgado Primero Civil, Sentencia 052 de 2017). ${ }^{5}$

El escenario de violencia después del año 2000 desplaza a cientos de indígenas de la cuenca alta del río San Juan a Bogotá, Medellín, Cali, Pereira y otros municipios del interior del país. En Bogotá las autoridades prestan atención en 2007 “después de que varios bebés [Embera] murieron por desnutrición en los hospitales Santa Clara y Samper Mendoza” (Castillo y López, 2011, p. 2). Las primeras acciones son de corte punitivo, los niños son custodiados por el Instituto de Bienestar Familiar (ICBF) y se culpabiliza a las madres como irresponsable e irracionales. Las tensiones entre las prácticas Embera para subsistir en la ciudad y la respuesta institucional crea un conflicto cultural bajo la noción de emergencia Embera, al finalizar la primera década del nuevo siglo (Castillo y López, 2011).

Alrededor de la emergencia Embera han surgido informes descriptivos que analizan el modo en que estas comunidades viven en ciudades como Bogotá, Pereira y Cali (Vía Plural, 2009; Mejía, 2007; coDHEs,

5 En lo que respecta al municipio de Tadó (Chocó), según la Red de Nacional de Información (RNI) de la Unidad de Atención y Reparación Integral para las Víctimas (UARIV), entre los años 1997-1999 se desplazan 904 personas, mientras que entre los años 2000-2002 se registran 6.593 desplazamientos. Por su parte, en el municipio de Pueblo Rico (Risaralda), durante los años 1997-1999 se desplazan 840 personas y entre los años 2000-2002 se desplazan 4.855 personas. 
2014). Estos estudios destacan de qué manera los procesos de desterritorialización en la ciudad transforman las prácticas alimentarias, económicas y culturales, y las dificultades para apropiar las lógicas urbanas. La mendicidad emerge como una práctica recurrente para subsistir en los contextos urbanos; esto deriva en una inversión de los roles de género, pues la mujer se erige en el sostén de la familia (Castillo y López, 2011; Cortés, 2013). Asimismo, los documentos resaltan la construcción de la alteridad Embera como un objeto de intervención que necesita de la ejecución de proyectos y programas para solventar la condición de extrema pobreza, especialmente la mendicidad y la desnutrición de niños y niñas. ${ }^{6}$

En el 2013, la Organización Regional Embera Wounaan (OREWA) elaboró el Plan de Salvaguarda del Pueblo Embera. ${ }^{7}$ El documento identifica las condiciones sociales de las comunidades que viven en los resguardos e incluye un apartado especial sobre las comunidades desplazadas que habitan asentamientos dispersos como las comunidades de Puerto Boyacá y otros municipios del Magdalena Medio. En el marco del reciente conflicto armado, la OREWA ha identificado un vínculo entre el desplazamiento forzado y una ola de migraciones ocurridas durante la mitad del siglo XX. Las migraciones están relacionadas con la colonización de

6 La acción institucional también ha promovido programas de retorno y reubicación. Por ejemplo, la Alcaldía de Bogotá y la UARIV acompañaron un proceso de retorno de 300 familias Embera al resguardo Tahamí, en el Alto Andágueda, para cumplir la primera sentencia de restitución de tierras (Sentencia 007 de 2014). Sin embargo, el seguimiento al proceso de retorno y reparación no ha garantizado el restablecimiento de los derechos fundamentales de las comunidades del resguardo Tahamí (Contraloría General de la República, Defensoría del Pueblo y Procuraduría General de la Nación, 2016; Comunidad de Juristas de Akubadaura, 2017). Según los abogados indígenas que acompañan el proceso, no se cumplieron los acuerdos pactados y los programas que se exhiben anteceden el retorno. En visto de lo anterior, el retorno es percibido como un instrumento para desalojar, negar y ocultar la presencia Embera en las principales ciudades del país (Comunidad de Juristas de Akubadaura, 2017).

7 Dicho plan fue elaborado en el marco del Auto 004 de 2009 de la Corte Constitucional, que es un acto de monitoreo de la Sentencia T-25 de 2004 de esta Corte, sobre el estado inconstitucional de la población indígena víctima del conflicto armado. 
baldíos y el acceso a nuevos lugares de trabajo rural por parte de los Embera, en departamentos como Putumayo, Caquetá y la región del Magdalena Medio. La migración permitió crear redes o circuitos que fueron utilizados para recibir a la población desplazada y desterrada en el marco del reciente conflicto armado.

\section{Narrativas territoriales y territorialidad Embera}

Según los mayores Embera, el vínculo con el Magdalena Medio surge en la década del 60-70 cuando los hombres jóvenes y solteros, entre los 12 y 20 años, se integraron a las dinámicas de adecuación, siembra y cosecha de maíz, ajonjolí, arroz y plátano. El arribo estuvo acompañado de los afrochocoanos, quienes servían como enlace para que el hombre Embera adquiriera trabajo. Esta información sorprende inicialmente, ya que la imagen del Embera de Puerto Boyacá hoy en día se reduce a la de víctima y desplazado.

La recurrencia de los relatos del trabajo agrícola en todos los mayores Embera despertó la curiosidad investigativa y abrió el campo para estudiar el vínculo de las dos comunidades Embera de Puerto Boyacá con el Magdalena Medio. La revisión documental mostró que durante la década de 1970 el municipio de Puerto Boyacá concentró un elevado porcentaje de tierra titulada a familias campesinas, en el marco de la reforma agraria adelantada por el Instituto Colombiano de la Reforma Agraria (INCORA), es decir, el contexto político agrario de economía campesina en Puerto Boyacá coincidía con los relatos de los mayores Embera.

A raíz de las nutridas descripciones y reflexiones de los y las indígenas de Puerto Boyacá, el presente documento despliega un análisis narrativo y territorial para abordar el destierro y desarraigo derivado del conflicto armado, así como su continuidad con las prácticas territoriales que le precedieron, es decir, la transformación de sus patrones de asentamiento y las excursiones laborales fuera del Alto San Juan. El análisis sobrepasa el escenario de violencia y enfrentamiento armado, 
para entrar a identificar y entender el rol de las experiencias cotidianas en la producción y transformación del espacio.

Por una parte, el análisis narrativo implica desmenuzar el conjunto de relatos construidos durante el trabajo de campo, para identificar sus sentidos, estructuras, oposiciones internas y relación con otros relatos (Kofes, 1998). Bajo esta mirada, los relatos son productos sociales que revelan la singularidad de un sujeto, individual o colectivo, atravesado por relaciones objetivo-afectivas que dan lugar a descripciones y reflexiones desde una dimensión subjetiva (Kofes, 1998). Por su parte, analizar los relatos desde una dimensión territorial implica acentuar las descripciones y experiencias geográficas de control o pérdida de dominio inscritas en los relatos, en área donde se superponen diversas fuentes de autoridad, intereses y nociones de territorio (Agnew y Oslender, 2010; Haesbaert, 2013). El análisis transita desde el recuerdo personal y cotidiano hasta los marcos colectivos de relación territorial. En este sentido, las narrativas no se circunscriben exclusivamente al lugar de origen (Alto San Juan) o al lugar de recepción (Puerto Boyacá), sino que refieren y pertenecen a un circuito territorial, esto es, un conjunto de localidades donde transitan personas, bienes y representaciones que entrelazan la noción de territorio y red (Clifford, 1994; Haesbaert, 2013).

La noción de circuito territorial deriva de la lectura del concepto de territorialidad y diáspora. Por territorialidad se entiende aquella capacidad y estrategia para clasificar, comunicar y controlar los elementos y personas del espacio geográfico que propician sentidos de posesión y permanencia (Sack, 1986; Nates, 2011). La territorialidad implica un complejo normativo formal e informal que intermedia las relaciones entre las personas con el espacio y es resultado de voluntades, tensiones y negociaciones bajo un entramado de relaciones de poder. Por su parte, la noción de diáspora refiere al conjunto de circuitos que rearticulan localidades, temporalidades y procesos de identificación, en un esfuerzo por crear nuevos terrenos de pertenencia entre trayectos y lugares (Clifford, 1994). El conjunto de conceptos a través de la noción 
de circuito territorial tiene un componente discursivo que analiza cómo diferentes actores representan las experiencias de destierro, desarraigo y elaboración territorial, es decir, que se selecciona, oculta y rechaza. Igualmente tiene una dimensión práctica que deriva en un conjunto de intervenciones y modelos de actuar que "se lleva consigo para desde allí dar sentido al espacio físico con que se topan en sus travesías o asentamientos temporales” (Nates, 2011:215)

El antropólogo peruano Gerardo Damonte (2011) utiliza el concepto de narrativa territorial para referirse al conjunto de discursos y prácticas circunscritas a espacios que están atravesados por relaciones de poder. Su método apunta a comprender las condiciones bajo los cuales se elaboran relatos que sirven de sustento para producir territorios (Nates, 2011; Damonte, 2011). Damonte argumenta que las narrativas territoriales no son sinónimos de territorios, mientras el territorio es un proyecto político que hace parte de un proceso de lectura que selecciona, recorta y delimita el espacio a través de múltiples intencionalidades que deliberan y chocan (Fernandes, 2009). Las narrativas territoriales son procesos de rememoración y selección de base histórica y espacial que constituyen sentimientos de pertenencia y solidaridad, que son el sustento para producir territorios (Damonte, 2011).

En este sentido, las narrativas territoriales se inscriben bajo una noción constructivista y política que refiere a prácticas de uso, percepción y producción, que transforman el espacio abstracto en un conjunto de territorios que se movilizan, chocan y aglutinan. Asimismo, las narrativas territoriales sirven como base discursiva de los procesos de transformación y proyección de relaciones de poder sobre el espacio, acentuando prácticas y representaciones cotidianas que se enmarcan en un contexto atravesado por la relación violencia-territorio (Carballeda, 2015). Bajo esta perspectiva se presenta y analiza el relato del mayor Embera Katío de Puerto Boyacá, Manuel Dovigama, para ilustrar cómo opera la territorialidad Embera. 
Manuel nació en la vereda Cinto, del corregimiento de Santa Cecilia [Pueblo Rico, Risaralda], después de los seis años Manuel se fue con su tío al río Condoto en la vereda Avelino [sobre la altura del río Condoto que desemboca en el San Juan] a hacer trampas de cacería y pescar de día en el monte. En las noches Manuel acompañaba a su tío a cazar con cerbatana (...) A los 13 años Manuel era soltero y vino a trabajar a Puerto Boyacá con su hermano mayor (...) el camino demoraba 2 días para coger la ruta Pereira-Dorada y después a Puerto Gutiérrez [Puerto Boyacá]. Manuel a los 16 años se casó con su esposa del territorio de Conondó [Bagadó, Chocó]. Allí trabajaron durante un año con la familia de ella [cuñados, suegros]. Después Manuel y su pareja abandonaron Conondó y se fueron a la vereda Avelino. Allí Manuel y su esposa empezaron a abrir finca en el monte, en esa finca crió a toda su familia (...) después Manuel se fue a la vereda Alto Silencio [en lo alto de la quebrada Anamugra, municipio de Tadó] (...) Manuel y su familia [así como las familias de sus hijos mayores] vivían entre Avelino y Alto Silencio (...) así duraron por lo menos 20 años de convivencia (...). Manuel nuevamente se trasladó al resguardo Peñas del Olvido [Tadó, Chocó]. Al llegar empezó a construir su casa y buscar un lote. Cuando encontró lote comenzó a cultivar diversos alimentos para su sustento. Allí se hicieron adultos sus hijos e hijas, cada uno fue a formar un hogar. Manuel duró 7 años en Peñas del Olvido, luego se trasladó nuevamente a la vereda Alto Silencio por cinco años (...) luego Manuel regresó a Peñas del Olvido y recuperó sus cultivos abandonados (Diario de campo, ${ }^{8} 2019$ ).

El relato permite observar que la territorialidad Embera es móvil y nace de uniones maritales y de prácticas de agricultura-cacería. Según Ulloa, Rubio y Campos (1996), la territorialidad Embera se compone de una relación dinámica entre: a) áreas productivas colectivas y privadas ,en relación a la cacería y rotación de cultivos-, b) áreas sociales y c)

8 El Diario de campo es el documento que recoge los relatos recolectados por el joven Embera katí Adán Restrepo, de la comunidad Katío y el joven chamñi Dagoberto Leiva de Puerto Boyacá, a quien se le encomendó escribir las historias de los adultos, prestando interés a los lugares donde han vivido y que han visitado, así como las prácticas y recuerdos que les evocaba cada lugar. 
áreas simbólicas individuales y colectivas habitadas por jais o seres que hacen parte del mundo chamánico Embera. ${ }^{9}$ La interrelación de las áreas simbólicas que producen los jais en el espacio hace parte de las nociones de verticalidad de la territorialidad Embera. La verticalidad refiere a la interrelación entre diferentes dimensiones simbólicas que son habitadas por seres que tienen diferentes repercusiones en las prácticas cotidianas de los y las Embera (Ulloa et al., 1996). De esta manera, la verticalidad entrelaza diferentes nociones del territorio, por ejemplo, las zonas de caza en la espesura de la selva son tierras comunales, no tienen propietario, pero tienen la potencialidad de ser intervenidas y transformadas en lotes de cultivo para sostener una familia. Igualmente, el equilibrio del espacio comunAL de la selva es resultado de la influencia de los jais, por esta razón las zonas de bosque primario, en especial las cabeceras de los ríos, son denominadas en ciertas ocasiones con el término /jaidé,/ que traduce casa de jais.

Bajo este marco, en el relato se puede distinguir que los lugares de habitación que tiene Manuel están relacionados con periodos de su vida que motivan diferentes prácticas espaciales. Por ejemplo, la juventud es protagonizada por sentimientos de búsqueda de trabajo. En su soltería, Manuel salió del Alto San Juan hacia municipios del Magdalena Medio como Puerto Boyacá y La Dorada en busca de trabajo agrícola. En esa época, los jóvenes-adultos afros del Chocó acudían a los padres de un muchacho Embera para poder llevárselo consigo a trabajar en cultivos de maíz o para tumbar monte, “yo era niño, el compromiso del negro con mi mamá era que volviéramos los dos” (Fragmento de entrevista,

9 A pesar de que los mismos Embera traducen el término jai como espíritu, los jais difieren considerablemente de la noción de espíritus de la tradición judío-cristiana, en la cual estos son seres inmateriales e inteligentes. Una correcta aproximación de los jais desde el castellano puede ser el de bestias salvajes, demonios o bestiario chamánico (Pardo, 1992). La noción de bestiario chamánico refiere a las jerarquías y relaciones que configuran el mundo de los jais. Según Pardo (1992), la heterogeneidad de los jais puede agruparse en siete categorías: a) jais de curación, b) jais de agresión o defensa, c) monstruos de los sitios, d) los dueños de las especies / wandra/, e) jais de culebra, f) jais de muertos y g) los jais exóticos y modernos. 
2019). Cuando Manuel establece familia finaliza sus circuitos laborales e inicia la búsqueda de tierras de cultivo de uso privado dentro de la región del Alto San Juan. Manuel se dirige donde familiares ascendentes suyos o de su pareja para recibir tierras de cultivo (padres o tíos), por lo cual hay un amplio abanico de selección que "se pudo dar mientras la zona del Pacífico estuvo relativamente despoblada y los migrantes no tenían dificultad para encontrar tierras" (Pardo, 1983, p. 624).

En el relato, se entrevé que el rol de la cacería se extiende más allá de las prácticas alimentarias, ya que sirve como mecanismo de exploración para distinguir sitios propicios de cultivo y habitación. La instalación de nuevos hogares construye un circuito de trayectos que varían según las condiciones del ecosistema, la fertilidad de los suelos, las cosechas y la abundancia de proteína animal de caza. Es decir, la territorialidad Embera es móvil y el conjunto de asentamientos ofrece opciones de alojamiento que permiten el restablecimiento del ecosistema y enfrentar las limitaciones o dificultades de una localidad.

Hay un elemento central de la territorialidad Embera que puede complementarse con el relato del hijo mayor de Manuel, José Vicente.

En Silencio trabajaron seis años y después se fueron a la cabecera del río Andágueda en Cuajandó a buscar tierra. Cuando consiguieron tierra, regresaron a recoger al resto de la parentela y se fueron todos a vivir allí. Las familias comenzaron a trabajar entre los cultivos y casas de Silencio y Cuajandó. Así duraron dos años hasta que murió un niño de 9 años y un joven de 16 en Cuajandó por mordedura de culebra, eso los aburrió y volvieron a Silencio. Después, en Silencio, murió un bebé de José Vicente, por eso se aburrieron y se fueron a trabajar en la finca Agua Bonita de un patrón paisa (Diario de campo, agosto de 2019).

La territorialidad Embera se constituye no solo por el área física donde circulan, sino también por su visión de mundo que entrelaza el cuerpo y el espacio a través de la presencia y relación con los jais Los Em- 
bera conciben que el cuerpo y el espacio pueden ser penetrados por jais, y por tanto pueden ser fuente de ataques y maleficios corporales que producen síntomas de diarrea, vómito, mordedura de culebras o muerte, mientras que en el ámbito espacial estos tienen la capacidad de aumentar o disminuir los animales de caza. El potencial riesgo que representan los jais requiere la acción de los especialistas espirituales o jaibanás, quienes son los interlocutores del bestiario chamánico para elaborar y regular prácticas de cuidado, control y hostilidad entre los miembros de una parentela o comunidad, así como ser elementos de socialización del territorio (Pardo, 1992; Ulloa et al., 1996) ${ }^{10}$. El jaibaná es una figura que tiene el potencial de degradar los suelos y la salud de una persona, a través de maleficios “que enferman como un camaleón que chupa el alma del niño o territorio y se fortalecen con el mal humor de la gente” (Diario de campo, marzo 2019). Es decir, los jaibanás son motivo de enfermedad, pero simultáneamente son elementos de cura y alivio con efectos directos en la territorialidad Embera.

El relato de José Vicente -quien hoy en día es uno de los principales jaibanás de la comunidad Katío de Puerto Boyacá-, aunque directamente no menciona el rol de los jais, si deja entrever que los asentamientos se abandonan ante la muerte de un neonato. Para el pueblo Embera la muerte está asociada con los jais, de ahí que una muerte sea motivo para decidir permanecer o abandonar un lugar. Según lo anterior, el conjunto de asentamientos que compone el circuito territorial de Manuel y su descendencia está ligado con los lazos de parentesco e intercambios matrimoniales, la fertilidad de los suelos, la abundancia de proteína animal, el acceso a lugares de trabajo agrícola y el equilibrio simbólico-espacial-corporal de los jais.

10 Según Losonczy (2006) la figura del jaibaná es central desde la dimensión sociopolítica. Los jaibaná son mediadores, ellos negocian entre el espacio onírico-espiritual y el espacio comunitario, asimismo sus acciones pueden producir desplazamientos o escisiones en una comunidad por un modelo generalizado de hostilidad entre jaibanás. 


\section{Entre los escenarios de terror y refugio}

Retomando la relación entre el Alto San Juan y el Magdalena Medio, Manuel señala que no era el único Embera que trabajaba fuera del Alto San Juan. Centenas de trabajadores Embera ocuparon la oferta laboral agrícola del Magdalena Medio desde la década de 1960. Los hombres se instalaban por periodos de ocho meses o un año, luego regresaban al San Juan para entregar remesas a las madres, e iniciaban de nuevo sus incursiones por el Magdalena Medio que era vista como una región prospera y un lugar propicio para acumular dinero.

Aunque generalmente la familia Embera no salía de la región del San Juan, algunas realizaron largos trayectos a diferentes regiones como el Magdalena Medio, Putumayo, Caquetá, Nariño y Cauca. Cuando la familia transita más allá del Alto San Juan extiende el circuito territorial e integra nuevas dinámicas propias de la región que la recibe. En el caso del sur del Magdalena Medio, las familias Embera adoptaron un modelo de vivienda denominado "campamentero", nombre con el que se designa el proceso mediante el cual una familia indígena se traslada a una hacienda bajo contrato verbal y temporal. Generalmente se construía un precario campamento de madera y palma y se residía el tiempo que veía conveniente el patrón. El modelo campamentero es fundamental en la historia de los Embera apellidados Leiva, de Puerto Boyacá, que son de filiación Chamí. Su memoria se distancia de la experiencia Katío de la descendencia de Manuel, porque la vida campamentera no estaba compuesta por jóvenes solteros en busca de trabajo, sino de familias y parentelas que salieron del Alto San Juan para instalarse en estancias laborales de Puerto Boyacá, con el objetivo de adquirir y colonizar tierras.

La historia de Juan Leiva permite comprender y analizar la experiencia campamentera que conecta al Alto San Juan con el Magdalena Medio bajo prácticas territoriales Embera. Este recuento es construido por su nieto, Greison Leiva, a partir de sus recuerdos y de conversaciones con su madre y un tío, en el marco de esta investigación. Su relato es de 
especial importancia, porque implica un tránsito entre el recuerdo, la narración y un proceso de recorte y selección de acontecimientos; no en vano inicia con el título La historia de mi pueblo.

Belarmina y Juan se conocen en Puerto Araújo (Cimitarra, Santader) y juntos se van para la vereda Guanegro de lo que hoy es Puerto Boyacá. En Guanegro instalaban campamentos en las fincas que se los requería, Juan Leiva aserraba y cultivaba maíz, ajonjolí y arroz, mientras que Belarmina realizaba tareas de cocina. En Guanegro tuvieron su primer hijo y adquirieron una pequeña finca sobre el río Guaguaquí. Mientras trabajaba Juan Leiva intercambiaba con los demás Embera que trabajaban en el área, allí les contaban sobre las abundantes tierras del San Juan; uno de los Embera decide venderles tierra del San Juan (...) pero los nativos de allá no querían a Juan Leiva, era un Embera sin conocidos en la región, le quitaron la finca recién adquirida y le metieron una puñalada. Los Leiva tuvieron que retornar al Magdalena, esta vez se instalaron nuevamente en Guanegro y lograron tener un pequeño lote en las proximidades de Guanegro, en lo que hoy se conoce como Los Naranjos (...). En esa época se formó la violencia en Boyacá, los Leiva y todos los jornaleros Embera del área se desplazaron a Puerto Berrío [Antioquia], cuando la violencia llegaba a Berrío se desplazaban de nuevo a Los Naranjos, pero esta vez los Leiva no se amañaron. Después de la guerra los Leiva se fueron de nuevo al San Juan a ocupar y rescatar la tierra adquirida en el pasado, allí nacen seis hijos en la vereda Fiabra [Pueblo Rico]. Nuevamente la sociedad indígena no los recibe (...), se dirigen al río Ité, abren selva y se instalan cinco familias (...) hasta que fueron masacrados por la guerrilla que operaba el área, allí mueren dos de sus hijos. Los sobrevivientes deciden, de la mano de un yerno [Saulo Dovigama], regresar al San Juan en las cercanías del corregimiento de Santa Cecilia sobre la quebrada Amurrupá (...) En 1990 los principales adultos de las familias de Amurrupá son masacradas por la guerrilla, el evento desplazó a los sobrevivientes al Magdalena Medio y por eso hoy existe la comunidad de Motordochake (Diario de campo, 2019). 
El relato que realiza Greison tiene un hecho en particular que se diferencia del de Manuel. Aquí se distingue una estructura dramática de oposiciones que recuerda al Alto San Juan bajo una imagen hostil que atenta contra su familia y a Puerto Boyacá como un refugio que permite afrontar la tragedia del desarraigo. La masacre de Ité, como elemento narrativo, elabora una experiencia colectiva que sirve como acto violento fundador para la familia Leiva. Según el filósofo francés Paul Ricoeur (2004), las experiencias colectivas de horror pueden transitar entre el recuerdo personal y su narración, para tramitar los sucesos traumáticos bajo una experiencia colectiva capaz de generar un efecto de deuda moral que debe ser reparada. En este sentido, el relato construido por Greison es una práctica política para visibilizar experiencias de violencia que deben ser reparadas. Este es un elemento de especial interés, ya que el reconocimiento de su condición de víctima ha enfrentado dificultades por ocurrir antes de la legislación nacional referente a las víctimas del conflicto armado. De esta manera, los relatos se ubican en escenarios de confrontación, en contra de silencios que pueden ocultar hechos de violencia y reparación de esta.

Como se observa en el relato, la familia Leiva tiene un circuito entre el Alto San Juan y Puerto Boyacá, que está enmarcado bajo representaciones de abundancia en disponibilidad de tierras y trabajo. No obstante, a pesar de representar a Puerto Boyacá como un escenario de prosperidad y refugio, el relato omite las condiciones de arribo al Magdalena Medio, que en otros relatos son caracterizadas por el sufrimiento, la incertidumbre y la marginalización. El desplazamiento y llegada a Puerto Boyacá implicó reproducir un modelo campamentero, que depende exclusivamente de la voluntad de los ganaderos para ofrecer asentamientos temporales. De esta manera, el destierro Embera en el Magdalena Medio deriva en una experiencia incompleta, extraterritorial como la denomina el sociólogo Louidor (2016), porque suspende la experiencia de una generación “en un espacio anónimo, sin dirección, ni orientación” (p. 180). 
Mientras Puerto Boyacá se percibe como un refugio a pesar de la marginalidad, el control de los grupos armados en el Alto San Juan transforma los territorios en escenarios de disputa, riesgo y horror. El conflicto armado deriva en la degradación simbólica y material del territorio Embera del Alto San Juan, tal como lo ilustra el siguiente relato:

A lo último hacían reunión tres grupos: FARC, ELN y ERG. Los demás compañeros de Risaralda ya embarcaban al menos dos muchachos a cada grupo. Nos decían que nosotros trabajábamos con paramilitares, nos decían ustedes tienen armas debajo de la tierra, y nosotros teníamos miedo, pero decíamos, tráigame al hombre que nos inculpa acá para decir donde tenemos (...) entonces comenzamos a discutir hasta que dijeron, por favor véndanos una novilla para comer y hacer la asamblea, luego de eso se llevaron dos muchachos por la mala y dejaron 3-4 milicianos. Entonces por no morir empezamos a trabajarles (...) después fueron los paramilitares, una vez salimos a un congreso en Quibdó y había un retén del ejército, ipara dónde van?, ustedes son guerrilleros nos decían (...) después había otro reten y eran paramilitares, nos sacaban cuchillos y restregaban en el pecho (...) en el congreso la OREWA nos decía que ahorita está puto, hay puro paramilitar que está matando emberas (Diario de campo, 11 de marzo 2019).

Durante la narración de estos fragmentos se presentaban irrupciones inesperadas en los tonos de la voz, acompañadas de un lenguaje corporal agresivo e impredecible que imitaba los gestos que realizaban los miembros de grupos armados durante las intimidaciones o amenazas. El carácter no discursivo que acentúa la corporalidad del proceso de rememoración está enmarcado en lo que Ricoeur (2004) denomina memoria impedida, que refiere a un conjunto de imágenes y recuerdos que pertenece a espacios privados e íntimos que difícilmente se pueden verbalizar.

La noción de memoria impedida se puede relacionar con la noción de "geografías del terror”, para analizar las manifestaciones espaciales de comunidades locales insertas en escenarios de miedo y terror (Oslen- 
der, 2008). Según el geógrafo escoses Ulrich Oslender, el terror tiene una dimensión espacial que se desarrolla en la relación cotidiana con el espacio a través de imágenes, objetos y relatos que transforman los lugares representativos de una comunidad en áreas hostiles que albergan experiencias traumáticas. En este marco el Alto San Juan, para la familia Leiva, pasa de ser un lugar de origen a ser el espacio físico de una masacre, mientras que para las familias Katío del Alto San Juan las restricciones a la movilidad — retenes, amenazas y prohibiciones - son indicadores de deterioro territorial, ya que hay un impacto directo en la libre circulación, por ejemplo, en las incursiones selva adentro para cazar y rotar los cultivos.

El impacto del miedo, la violencia y el terror degrada la experiencia territorial en el Alto San Juan; el conflicto no solo amenaza la vida, "la imagen de su irrupción en el paisaje y su acción sobre el cuerpo, el tambo [palabra Embera para casa], la finca, los cultivos dan cuenta de la representación de la violencia como un daño sobre el territorio" (Cortés, 2013, p. 50). Caracterizar el Alto San Juan como parte de las geografías del terror permite comprender el abandono de los territorios no solo desde su dimensión material, sino desde las implicaciones simbólicas que repercuten directamente en las dinámicas de los circuitos territoriales.

Las geografías del terror transforman las experiencias de destierro en experiencias de desarraigo, porque la pérdida de tierra por medios violentos (destierro) se interpreta y experimenta desde construcciones sociales que pueden generar rupturas que deterioran o arruinan la capacidad de sostener referentes territoriales (desarraigo) (Aguilar, 2017; Louidor, 2016). En este marco las narrativas territoriales son una ventana para prestar atención a procesos sociales complejos, que brindan un conjunto de representaciones que sirven como indicadores para reconocer el impacto de la violencia en las dinámicas territoriales y sentidos de pertenencia de las comunidades indígenas. 
El contexto de degradación del Alto San Juan se intensifica durante la incursión paramilitar en el año 2000. Las comunidades Embera quedan en medio de un enfrentamiento armado que deriva en el desplazamiento de cientos de familias de la región. En este escenario, un pequeño grupo de ocho familias nucleares Katío del resguardo Peñas del Olvido (Tadó, Chocó), de la parentela de Manuel Dovigama, se dirigió al sur del Magdalena Medio, aquella región que en la juventud de Manuel fue prospera y favorable para el Embera.

Nosotros nos vinimos a Boyacá porque mi papá jornaleaba en Puerto Boyacá cuando jóven. Entonces nos desplazamos, primero paramos en La Dorada [Caldas], estuvimos mendigando por una semana, nos fuimos de allí porque decían que el ICBF venía a recoger a los niños. En Puerto Boyacá nos encontramos al compañero Gerardo Leiva [hijo de Juan Leiva], él era compañero de mi papá [Manuel Dovigama] en Santa Cecilia y su mujer [nacida en Guarato a escasos kilómetros de Peñas del Olvido] es familiar de mi papá. Él nos ayudó y dijo que hiciéramos un rancho en carremuleros [invasión en la orilla del río Magdalena], dijo: venga para acá, yo vivo en casita malita. Allí duramos tres años al lado del río Magdalena. Antes era una playa y vivían puros desplazados (Diario de campo, 11 de marzo 2019).

A pesar de la imagen del Magdalena Medio como un escenario de prosperidad, la experiencia inicial de la parentela de Manuel se caracterizó por la mendicidad, la marginalidad y la estigmatización en los cinturones de miseria del casco urbano de Puerto Boyacá. Sin embargo, la ausencia de una confrontación armada en el sur del Magdalena Medio o relativa calma del orden paramilitar, facilitó que las familias Embera se instalaran bajo la imagen anónima del desplazado por la violencia.

La parentela de Manuel fue recibida por una porción de las familias desterradas de Amurrupá, que para evitar el pago de arriendos decidieron instalarse en la orilla del río Magdalena, sobre la cabecera municipal, al finalizar la década de 1990. Los recuerdos de Manuel, de prosperidad en Puerto Boyacá, se desdibujan, pues las familias que lo recibieron le se- 
ñalaron un contexto regional regulado por el paramilitarismo. A quienes llegan se les indica que la abundancia de trabajo agrícola ha finalizado, que la nueva bonanza es la cocalera en la serranía de Las Quinchas. Rápidamente los hombres Embera recién llegados se insertan en la oferta laboral de los cultivos de uso ilícito en la serranía, mientras las mujeres y los niños se quedan en precarios ranchos a la orilla del río.

El arribo de la parentela de Manuel a Puerto Boyacá y su acogida por parte de la familia Leiva permite observar que la experiencia Embera en la región del Magdalena Medio, en la década de 2000, empleó los circuitos construidos desde la década de 1960. Sin embargo, las representaciones de abundancia de tierra se transformaron en una experiencia ambivalente, controlada por los grupos paramilitares que solo permitió la alteridad indígena en los márgenes de su control: los barrios de invasión sobre la orilla del río Magdalena. Aunque la experiencia territorial en la orilla del río se caracteriza por su incapacidad para construir unos referentes territoriales estables, la oferta laboral de los cultivos ilícitos mantiene la noción de abundancia laboral, en un escenario de informalidad y escasez.

\section{Reubicación y producción de un territorio Embera}

El aumento de las familias Embera en la orilla del río, rápidamente llamó la atención de las autoridades locales. Para el año 2002, en Puerto Boyacá se reconocen dos focos de asentamientos indígenas sobre la quebrada Velázquez ${ }^{11}$ y sobre el río Magdalena (Min. Interior, 2004). Luego de una creciente del río Magdalena los asentamientos sobre el cauce debieron desalojarse y reubicarse en el coliseo municipal. Así

11 El conjunto de familias ubicadas sobre la quebrada Velásquez, en el centro poblado conocido como Kilómetro 11/2, vereda Puerto Niño, es el grupo que vivía sobre la isla del Guaguaquil. Las familias tuvieron que trasladarse luego que la creciente del río se llevó sus cultivos y casa. Pasada la inundación las familias lograron adquirir contratos que finalmente fueron el insumo para comprar una casa en el 1 y $1 / 2$ sobre la quebrada Velázquez a pocos kilómetros de la desembocadura del río Magdalena. 
comienza el trámite para reubicar a los y las indígenas en un predio rural de la Alcaldía Municipal, que en poco tiempo se bautizó como Motordochake Alto Nacabera dua.

La constitución de Motordochake inaugura nuevas experiencias y provee de nuevos insumos al circuito territorial de las parentelas desterradas, fragmentado por la violencia y el horror del Alto San Juan. Motordochake proveyó un escenario estable que permitió la re-circulación de los indígenas entre Puerto Boyacá y el Alto San Juan.

Un 25 de octubre en el año 2002 se estableció la comunidad Motordochake Alto Nacaber dua. La reubicación de las familias contó con el apoyo de la Alcaldía, que entregó 100 metros de plástico para que se construyeran ranchos cada familia, mientras se construían las casas de madera. Además del plástico les suministraron alimentación y atención en salud. La comunidad duró seis meses construyendo las casas con madera que fue traída de la serranía de Las Quinchas, por parte de la Alcaldía de Puerto Boyacá. Luego se adecuó el terreno con un sistema de mangueras y motobombas para suministrar agua potable de un caño a la comunidad.

Antes de llegar la comunidad la tierra era puro monte, una rastrojera sin un solo pasto. Entonces la comunidad comenzó a trabajar y cultivar. Las familias del Chocó se fueron a traer semilla de piña, borojó, chontaduro y achín, de sus antiguos lotes en Peñas del Olvido. Primero solo sembraron para ellos, hasta que comenzaron los problemas entre padres de familia, porque los niños y niñas se robaban los frutos. Entonces se hizo una reunión para acabar los robos y se repartió semilla a las demás familias, toda la comunidad tuvo sus cultivos de semilla del Chocó (Diario de Campo, 2019).

Como se ha hecho mención, las nociones de propiedad familiar Embera se basan en la relación suelo-cultivo; su territorialidad distingue zonas de cultivo familiar como una fuente de arraigo y sentido de pertenencia. El periodo que precede a Motordochake es de sufrimiento, en parte porque está ausente de cultivos propios y hogares estables. 
sufrimos mucho, aguantando hambre, hay veces que los hombres no les daba plata y no había para el arriendo y nos humillaban, esa cosa no podemos recordar, en ese momento no conocíamos alcaldía, escuela, hospital, solo nos decían que de pronto venían los de la ley del monte ... hasta ahora es que conocemos (...) cuando manteníamos desplazados no sabíamos nada. (Diario de campo, 19 de mayo de 2019).

La relación entre el relato de Motordochake y su experiencia predecesora de sufrimiento, cimenta nuevas asociaciones y oposiciones en la narrativa territorial de los y las Embera de Puerto Boyacá. En los dos relatos surge la Alcaldía como una figura que subsana el sufrimiento proveyendo tierra. La Alcaldía Municipal y el conjunto de entidades que participaron del Comité Municipal para la Atención Integral a la Población Desplazada por la Violencia (art. 7 Ley 387 de 1997) comienzan a percibirse como actores protectores, bajo la figura de un padre que abastece a su descendencia proveyendo suelos para cultivar, agua potable, escuela, casas y proyectos productivos. Por otra parte, el suelo del predio, antes de establecerse Motordochake, se describe como un rastrojo, es decir, un suelo abandonado que requiere de intervención, lo cual desde la territorialidad Embera implica la adecuación y siembra de cultivos, lo que motiva la proyección de cargas emotivas y afectivas con el espacio. De ahí que Motordochake transforme la experiencia e inicie un proceso de producción territorial que permite a las familias Embera construir un sentido de pertenencia sobre un área que intervienen, ordenan y simbolizan.

El filósofo francés Henri Lefebvre (2013) observa que el espacio social está compuesto por una triple dialéctica: a) prácticas espaciales; b) representaciones del espacio y c) espacios de representación. Las prácticas espaciales refieren a una dimensión percibida, sensible y física, basada en la estrecha relación entre la vida cotidiana y el conjunto de dinámicas de producción y reproducción que se proyectan sobre el espacio. En lo que respecta a la territorialidad Embera, sus prácticas espaciales refieren al conjunto de trayectos y acciones - relaciones de 
parentesco, siembra, cacería o recolección - en cada localidad que compone el circuito territorial.

Sin embargo, las prácticas sobre el territorio tienen diferentes connotaciones; su distinción es posible de identificar a través del concepto de representación del espacio que implica una dimensión concebida, abstracta y mental. Según Lefebvre (2013) las representaciones del espacio entrelazan relaciones de poder y saber, de ahí que alberguen tensiones, conflictos y solidaridades. Para las familias Embera las actividades agrícolas en Motordochake derivan en representaciones de propiedad, es decir, la transformación del rastrojo en cultivos conduce a la constitución de un lote o solar de propiedad familiar. Asimismo, Motordochake implica un conjunto de acciones representadas como ayudas, en busca de restablecer el sufrimiento durante la experiencia extraterritorial para reiniciar el circuito territorial con el Alto San Juan.

Por su parte, las representaciones espaciales desde la institucionalidad originan nociones de propiedad y productividad en el marco de la legislación sobre la atención y reparación a las víctimas del conflicto armado (Ley 387 de 1997, Decreto 2569 de 2000). Por otro lado, la institucionalidad representa a Motordochake como un escenario para contener y ordenar la alteridad indígena, que requiere de la elaboración de un sujeto colectivo de corte empresarial que se articule con el mercado local y sea responsable de su propio éxito, sostenibilidad y desarrollo social (Bocarejo, 2014; Katzer, 2015). Estas representaciones corporativas proyectan en Motordochake y su comunidad prácticas sedentarias que se enfrentan con la territorialidad Embera, en especial en su capacidad para construir circuitos, porque cuando la migración no hace parte del conflicto armado se concibe como un elemento de desorden y patología. En este sentido, las representaciones del espacio y de comunidad, a pesar de sustentarse en la relación saber/poder, en la práctica operan bajo juicios morales que legitiman la acción institucional y estigmati- 
zan las prácticas Embera como inconcebibles en un orden racional y moderno. $^{12}$

Por su parte, la noción lefebvriana de espacios de representación refiere a una dimensión relacional, vivida y social que se compone de cargas emotivas y afectivas, que en la comunidad Embera implica el equilibrio simbólico-espacial en donde los jais, la enfermedad, muerte, prosperidad y abundancia producen sentimientos de repulsión, apego y pertenencia. Las narrativas territoriales que se han presentado señalan la transformación del Alto San Juan en un escenario de horror y a Puerto Boyacá como escenario de refugio y posibilidad de arraigo. No obstante, la reubicación institucional en Motordochake ignora el rol del jaibaná en los procesos de territorialización y equilibrio espacial, aspectos que no se pueden contener en un predio de 57 hectáreas. De hecho, la relación de los jaibanás con Motordochake permite descifrar un territorio enfermo, un cementerio de los paramilitares que contiene jais malignos que afectan la salud de la comunidad, en especial de los neonatos.

\section{Segmentación de la comunidad y retorno al Alto San Juan}

Mientras la comunidad Embera de Puerto Boyacá re-construyó sus circuitos territoriales en Motordochake, las condiciones de violencia y degradación simbólica en el Alto San Juan se intensificaron. Esto aumentó el número de desterrados y desarraigados que evidenció la crisis del pueblo Embera a nivel nacional, que se expandió a las principales ciudades del país (CODHES, 2018). El escenario de violencia desterró a 19 familias Katío

12 Tal como se manifiesta en la intervención de un concejal, en la sesión del Concejo Municipal del 1 de agosto de 2018, a propósito de la titulación colectiva del predio Quindío o Motordochake a la comunidad: "Porque si miramos la cultura de ellos es más de recolección, no son agricultores, ellos son de pescar y recolectar desde su cultura ancestral. Me parece doctora, que el gobierno debería considerar no entregarles las 57 hectáreas a ellos [comunidad Embera]”. 
del sector Bajo Gito, resguardo Gito Docabú, municipio de Pueblo Rico, Risaralda, en el año 2009. Las familias fueron recibidas en Puerto Boyacá y se activó el protocolo institucional de atención a desplazados que proveyó asistencia alimentaria y alojamiento transitorio por 20 días en las instalaciones de la Defensa Civil.

Llegamos a Boyacá porque de joven trabajé doce años en la región (...), entonces luego que mi hijo desertó de la guerrilla, el grupo lo asesinó. Cuando yo declaré su muerte, la guerrilla comenzó a investigarme y decían que yo era un paramilitar (...) entonces llegamos a Boyacá (...) la Alcaldía nos recibió bien y nos alojó en la Defensa Civil por un mes (...) pero la envidia de otros indígenas [algunos de Motordochake] decía que no éramos desplazados; después la Alcaldía comenzó a investigar con la Alcaldía de Pueblo Rico y decían que nos fuimos por pasear, entonces nos dijeron que nos teníamos que devolver (...) como yo tenía familia en Motordochake nos invitaron a alojarnos porque sabían que no podíamos volver a Risaralda, las otras familias se fueron a Pereira a sufrir en la ciudad. (Diario de campo, 19 de septiembre de 2019).

El relato señala la negativa y las sospechas sobre la veracidad de los testimonios sobre el conflicto armado y sus repercusiones en familias indígenas. La opinión pública señaló que los indígenas arribaron a Puerto Boyacá con la expectativa de que les entregaría tierra como en Motordochake (Defensoría del Pueblo, 2017). De esta manera, la asociación inicial indígena-desplazado se transformó en indígena = falsa víctima, bajo el imperativo de evitar el crecimiento de la población de Motordochake.

A pesar de la negativa de recibir a las familias, tres de ellas logran ingresar a Motordochake. Su ingreso y permanencia generó un sin número de tensiones y conflictos intraétnicos que derivaron en la segmentación de la comunidad de Motordochake. El ingreso de nuevas familias incrementó la presión sobre las áreas de producción familiar, por lo cual los escasos lotes aptos para cultivo comenzaron a ser objeto de conflicto. Las diferencias respecto al uso de la tierra desataron un conflicto étnico 
que fracturó la comunidad en un grupo Chamí y otro Katío, luego del homicidio de un mayor jaibaná. La siguiente cartografía compara la distribución del espacio en Motordochake antes y después de la división de la comunidad (figura 2).

\section{Figura2. División de lotes de cultivo Motordochake antes y despues del conflicto étnico}

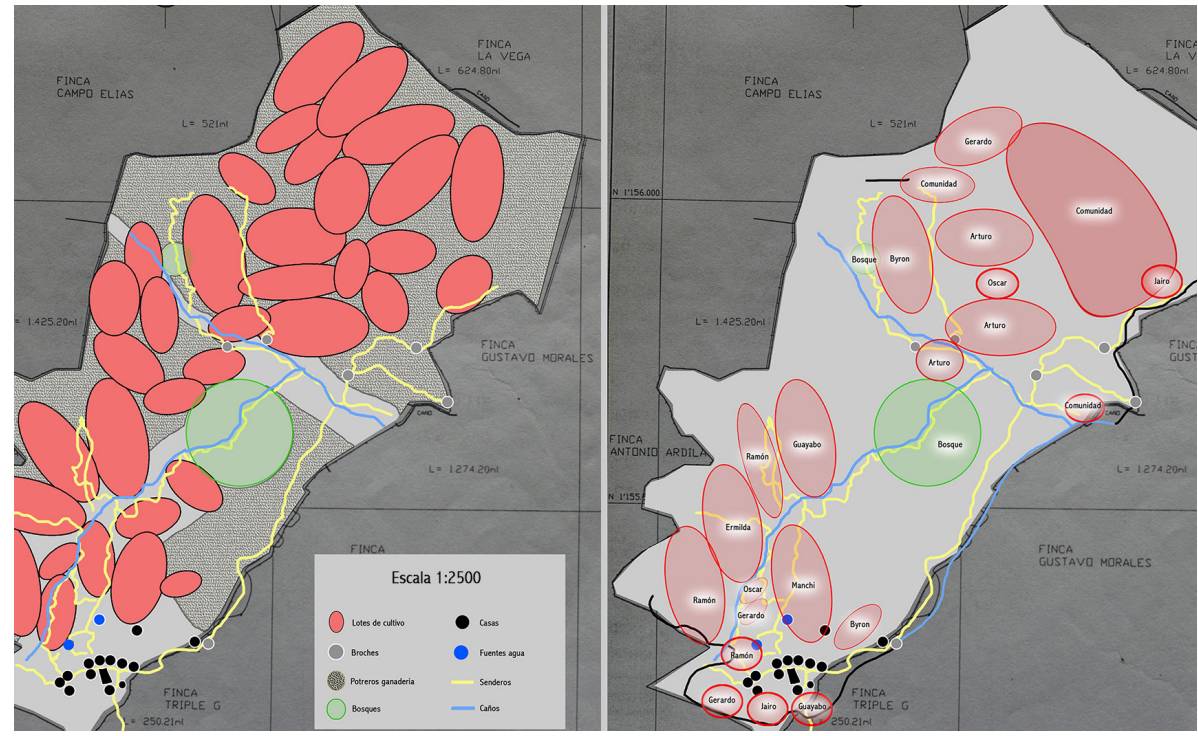

Fuente. Cartografía de la división de predios de Motordochake antes y después del conflicto, trazado sobre plano de la Secretaría de Planeación Municipal de Puerto Boyacá. Elaboración propia.

La imagen de la izquierda ilustra la presión sobre el suelo de las 57 hectáreas y la falta de capacidad para sostener el aumento de nuevos matrimonios entre las jóvenes parejas. En ella se aprecian zonas de pastos para sostener ganado de propiedad de algunos indígenas, pero los daños del ganado sobre los cultivos aumentaron los conflictos dentro de la comunidad. Por su parte, la imagen de la derecha ilustra la 
distribución de lotes de cultivos luego de la segmentación. La salida de las familias Katío disminuyó la presión sobre el suelo y facilitó un lote colectivo en la zona norte.

El homicidio de un jaibaná fue resultado de las tensiones internas que experimentaba esta población en constante crecimiento, asentada en un escenario de escases. Este hecho produjo consecuencias de orden político, cultural y territorial que: a) dividieron la comunidad; b) exacerbaron la adscripción étnica Chamí y Katío; c) visibilizaron la importancia de la figura del jaibaná; d) motivaron el abandono y retorno de 16 familias Katío a Chocó y Risaralda en el año 2012 y la permanencia en Motordochake de entre 9-12 familias de filiación Chamí. Una porción de las familias retornadas se dirigió a la quebrada Amurrupá, otra a Gito Docabú y otra al resguardo Peñas del Olvido.

El retorno les implicó el regreso a las geografías del terror y a las experiencias de miedo frente a los grupos armados que eran las autoridades territoriales de facto:

Cuando volví a Peñas tuve mi platanera, yuquera y reses. Allí fui cabildo por 8 meses, me eligieron gobernador, decían que yo sabía de eso por haber sido antes de ir a Boyacá, yo acepté (...) la guerrilla llamó a una reunión en la comunidad de Burbata, necesitaban al nuevo gobernador (...) llegamos y habían cuatro comandantes, habían marranos y comida, en la comunidad había un supermercado, una oficina con computadores y plantas de electricidad (...) uno de los comandantes me dijo: yo a usted lo conozco cuando era niño, usted es de las Peñas, usted se fue a Boyacá, y comenzó a investigarme (...) me decía que en Peñas hay mucho cochino, roban mucho, hay vendedores de bazuco, allá sapearon y mataron a nuestros compañeros, si usted quiere trabajar con nosotros y tener supermercado y oficina necesitamos que me traiga 8 personas de los cochinos (...) yo como era nuevo gobernador no sabía quiénes hacían los males (...) cuando fuimos al resguardo hicimos asamblea, el antiguo gobernador me decía que no entendía mi palabra, que la guerrilla me quería embolatar 
por ser nuevo, me decían que no iban a mandar ningún muchacho y que fuera solo donde el comandante (...) después volvimos a Boyacá (Diario de campo, 19 de septiembre de 2019).

Este relato señala que el retorno no está asegurado por la titularidad del suelo y su vinculación con un resguardo. Para la parentela el retorno implicó la rearticulación con las formas de organización interna del resguardo y por ende con las dinámicas territoriales de facto elaboradas y desarrolladas por los grupos armados. De ahí que el retorno no solo necesita de la aprobación de los grupos armados, sino que está íntimamente relacionado con las dinámicas de convivencia entre los retornados y aquellas familias que nunca se desplazaron, quienes pudieron profundizar las disputas internas compuestas por un conjunto de relaciones de solidaridad y hostilidad inherentes del mundo Embera.

En este caso, el retorno implicó un deterioro territorial, un contexto dominado por los grupos armados que objeta la caracterización de los lugares de origen y expulsión como escenarios inalterables y cuestiona la prevalencia del retorno en la política pública de víctimas. El retorno, antes que ser una técnica y solución para el restablecimiento de las condiciones que antecedieron el desplazamiento, originó una nueva ruptura que introdujo a las parentelas en un escenario hostil que produjo perturbaciones semejantes a las experimentadas en el primer desplazamiento forzado (Garzón, 2017), con la diferencia que la interrupción y perturbación es promovida por las agencias del Estado en el marco de la política pública de víctimas.

El fallido retorno al Alto San Juan implican el regreso a Puerto Boyacá y con ello las experiencias de ruina, por carecer de un espacio propio que pueda albergar al conjunto de familias Katío. Esto ocasiona una experiencia de sufrimiento que, por un lado, está compuesto por el desarraigo del Alto San Juan resultado de las geografías del terror y, por otro lado, del desarraigo de Puerto Boyacá como consecuencia del desborde de la estrategia institucional para ordenar y mantener la al- 
teridad indígena en Motordochake. De ahí que analizar el caso de las comunidades Embera de Puerto Boyacá permita ilustrar la complejidad y las dificultades derivadas de los escenarios de violencia y degradación territorial producidos por el conflicto armado que deben enfrentar los y las indígenas.

\section{Conclusiones}

El presente artículo ha abordado un conjunto de narrativas territoriales elaboradas por los y las Embera asentados en Puerto Boyacá, para comprender las transformaciones y continuidades de su territorialidad en escenarios de violencia desde su dimensión cotidiana. El análisis de las narrativas territoriales permite comprender que la violencia, el miedo y el horror no solamente atentan contra la integridad física de los y las indígenas, sino que el impacto se extiende a una dimensión territorial que entrelaza una dimensión discursiva y práctica del espacio. De esta manera se comprende que el destierro y el desarraigo no solo son resultado de amenazas directas sobre los sujetos, sino que también son derivados de un contexto de degradación que afecta la territorialidad Embera y resulta en destierros y desarraigos que son interpretados por la institucionalidad bajo prejuicios morales que juzgan y cuestionan la veracidad de los hechos.

El artículo describe y analiza cómo la intervención institucional en Puerto Boyacá ha elaborado un conjunto de prácticas que amparan asentamientos temporales que antes que restablecer el desarraigo producen escenarios de escasez, tensiones y conflictos internos de las comunidades indígenas. De esta manera, el caso revela que la política pública de víctimas, en su apartado sobre retornos y reubicaciones, no ha producido medidas para restablecer los derechos territoriales a través de un abordaje acorde con las dinámicas propias de circuitos territoriales Embera. De hecho, la intervención institucional ha sido un elemento de estigmatización que genera la noción de la irracionalidad indígena como argumento para explicar el mantenimiento del desarrai- 
go y la marginalización que experimentan los y las indígenas tanto en el Alto San Juan como en Puerto Boyacá.

El análisis ilustra que los procesos de destierro y de desarraigo producen procesos de territorialización que entrelazan, a manera de bisagra, la degradación simbólica del Alto San Juan y la elaboración de experiencias de refugio en Puerto Boyacá, a pesar de la marginalización y pérdida de autonomía. Es decir, las implicaciones territoriales del conflicto armado en la región del Alto San Juan sobre las comunidades Embera hacen parte de un complejo de relaciones que afecta el paisaje, fractura las relaciones comunitarias, instaura y mantiene sentidos históricos de refugio y abundancia en regiones que hacen parte de la territorialidad Embera, como por ejemplo Puerto Boyacá y el Magdalena Medio.

En este marco, la categoría de narrativas territoriales ofrece un conjunto de herramientas que entrelaza los estudios de la memoria con los estudios territoriales desarrollados por la geografía humana. Su conjunto permite articular un sistema de representaciones, emociones y prácticas colectivas, acentuando relaciones territoriales que entretejen dinámicas de producción y apropiación del espacio que dan sentido a la formación de sujetos, comunidades y territorios indígenas.

Por otra parte, el conjunto de categorías que destacan la dimensión territorial de las comunidades Embera, permite abordar las experiencias en Puerto Boyacá y el Alto San Juan como parte de procesos de territorialización que subrayan las fortalezas resultantes de una territorialidad móvil capaz de elaborar estrategias de resistencia en escenarios de segregación económica, social y cultural. De esta manera, los circuitos territoriales reconstruyen rutas y trayectos que hacen parte del conjunto de recursos territoriales que han utilizado las comunidades Embera para pervivir, mantener su alteridad indígena y producir territorios que transitan entre la informalidad y formalidad. 
Finalmente, cabe mencionar que las representaciones y prácticas de la territorialidad Embera son un complejo de atributos móviles y dinámicos que deben ser elementos a abordar durante los procesos de destierro y desarraigo, más aún cuando la violencia en el Alto San Juan (y otras regiones) se mantiene por el asedio de los grupos armados que subsisten. Concebir los efectos del conflicto armado en las comunidades indígenas desde una dimensión cotidiana y territorial permite problematizar las medidas de reparación de la política pública de víctimas. En este sentido, el análisis de las narrativas territoriales permite entender que el retorno no necesariamente debe ser el principal medio de reparación. Igualmente, la reubicación debe garantizar la operación en pleno de la territorialidad Embera, incluyendo la titularidad colectiva de los predios, ya que la informalidad y la escasez en Puerto Boyacá han resultado en una experiencia extraterritorial, ambigua o ambivalente, que desde el año 2002 mantiene a los y las Embera sin la capacidad de autonomía y autodeterminación, condiciones que hacen parte de una nación pluriétnica y multicultural.

\section{Referencias}

Agnew, John y Oslender, Ulrich. (2010). Territorialidades superpuestas, soberanía en disputa: lecciones empíricas desde América Latina. Tabula Rasa, (13), 191-213.

Aguilar, Javier. (2017). Relaciones territoriales de las víctimas del conflicto armado: una mirada desde Ciudad Bolívar (Bogotá, Colombia) (Tesis de maestría). Universidad Nacional de Colombia. Bogotá.

Asociación Orewa. (2013). Plan de salvaguarda pueblo Embera. Documento unificado planes regionales. Bogotá: Ministerio del Interior.

Bocarejo, Diana. (2014). Languages of Stateness Development, Governance and Inequality. En DesiguALdades.net, Working Paper No. 63. Berlin: International Research Network on Interdependent Inequalities in Latin America.

Carballeda, Alfredo. (2015). El territorio como relato. Una aproximación conceptual. Margen, (76). 
Castillo, Ángela y López, Jhonnatan. (2011). Familias emberas en situación de desplazamiento forzado en Bogotá: una encrucijada a la interculturalidad. Ponencia presentada en el VII Congreso y Curso Internacional Red Latinoamericana de Antropología Jurídica (Relaju). Pontificia Universidad Católica del Perú. Lima.

Clifford, James. (1994). Diasporas. Cultural Antrhopology, 9(3), 302-338.

Comunidad de Juristas de Akubadaura. (2017). Informe para el Tribunal Superior de Antioquia, Sala Especializada en Restitución de Tierras.

Consultoría para los Derechos Humanos y el Desplazamiento [Codhes]. (2014). Crisis humanitaria del pueblo emberá. En Documentos CODHES No. 28. Bogotá: Torre Gráfica Limitada.

Contraloría General de la República, Defensoría del Pueblo y Procuraduría General de la Nación. (2016). Informe de seguimiento al cumplimiento de la Sentencia de Restitución de Tierras No. 007 de 2014 y al Auto 025 de 2015 del Tribunal de Antioquia a favor del pueblo Embera Katío del Alto Andágueda.

Cortés, Oriana. (2013). Interpretaciones de la migración y el desplazamiento Embera, el caso de familias Embera Katío en Bogotá (Tesis de maestría). Universidad Nacional de Colombia. Bogotá.

Damonte, Gerardo. (2011). Construyendo territorios: narrativas territoriales aymaras contemporáneas. Lima: Grupo de Análisis para el Desarrollo/Consejo Latinoamericano de Ciencias Sociales/Fundación Tierra.

Defensoría del Pueblo. (2017). Informe defensorial. Derechos humanos de la población indígena Embera Katío, Chamí y zenú en situación de desplazamiento forzado ubicada en la jurisdicción de la regional del Magdalena Medio. Bogotá: Delegada para los Derechos de la Población Desplazada, Defensoría Regional Magdalena Medio.

Fernandes, Bernardo. (2009). Territorio, teoría y política. En Fabio Lozano y Juan Guillermo Ferro, Las configuraciones de los territorios rurales en el siglo XXI (pp. 35-61). Bogotá: Pontificia Universidad Javeriana.

Garzón, María. (2017). Las tácticas del habitar. Prácticas de recuerdos y resignificación de lugares en contextos de retorno de población (Tesis de doctorado). Universidad Nacional de Colombia. Bogotá. 
Haesbaert, Rogério. (2013). Del mito de la desterritorialización a la multiterritorialidad. Cultura y representaciones sociales, 8(15), 9-42.

Juzgado Primero Civil del Circuito Especializado en Restitución de Tierras de Quibdó. Sentencia 052 de 2017. Proceso de restitución de derechos territoriales resguardo indígena Embera Katío Mondo-mondocito.

Katz, David. (2019). Diseño de un modelo de gobernanza para mejorar el desempeño social y ecológico en la serranía de Las Quinchas en Otanche, Boyacá (Tesis de maestría). Pontificia Universidad Javeriana. Bogotá.

Katzer, Leticia. (2015). Márgenes de la etnicidad: de fantasmas, espectros y noMado-lógica indígena. Aportes desde una «etnografía filolítica». Tabula Rasa, (22), 31-51.

Kofes, Suely. (1998). Experiencias sociales, interpretaciones individuales: posibilidades y límites de las historias de vida en las ciencias sociales. En Thierry Lulle, Pilar Vargas y Lucero Zamudio (Coords.), Los usos de la historia de vida en las ciencias sociales (Vol. I, pp. 82-101), Barcelona: Anthropos.

Lefebvre, Henri. (2013). "Plan de obra” y “El Espacio social”. En La producción del espacio (pp. 63-216). Madrid: Capitán Swing.

Losonczy, Anne-Marie. (2006). Viaje y violencia. La paradoja chamánica emberá. Bogotá: Universidad Externado de Colombia.

Louidor, Woodly Edson. (2016). Articulaciones del desarraigo en América Latina. El drama de los sin hogar y sin mundo. Bogotá: Pontificia Universidad Javeriana.

Medina, Carlos. (1990). Autodefensas, paramilitares y narcotráfico en Colombia. Origen, desarrollo y consolidación. El caso "Puerto Boyacá". Bogotá: Editorial Documentos Periodísticos.

Mejía, William. (2007). Presencia Embera en el área metropolitana centro occidente. Pereira: Fundación Cultural Germinando/Fundación Bernard van Leer Holanda/Red de Universidades Públicas del Eje Cafetero.

Ministerio del Interior. (2004). Concepto sobre la pertenencia étnica Embera Chami y Embera Katío de la comunidad "Motor Duchake Alto Nacaberdwa" o "Quebrada Piedra Blanca Tierra de Nosotros", ubicada en la jurisdicción del municipio de Puerto Boyacá, departamento de Boyacá. Bogotá: Autor. 
Mosquera, Jefferson. (2011). Cambios y persistencias en el subsistema minero aluvial del territorio colectivo del consejo comunitario mayor del Alto San Juan-Asocasan (Tadó, Chocó): entre 1960 y 2010 (Trabajo de grado para optar por el título de ecología). Pontificia Universidad Javeriana. Bogotá.

Nates, Beatriz. (2011). Soportes teóricos y etnográficos sobre conceptos de territorio. Revista Co-herencia, 8(14), 209-229.

Oslender, Ulrich. (2008). “Geografías del terror”: un marco de análisis para el estudio del terror. Scripta Nova. Revista Electrónica de Geografía y Ciencias Sociales, 12(270).

Pardo, Mauricio. (1983). Transformaciones históricas en los indígenas Chocó. Boletín de Antropología, 2 (17, 18, 19), 611-627.

Pardo, Mauricio. (1987). Regionalización de indígenas Chocó. Datos etnohistóricos, lingüísticos y asentamientos actuales. Boletín del Museo del Oro, (18), 46-63.

Pardo, Mauricio. (1992). El convite de los espíritus. En Emanuele Amodio y José Juncosa (Comp.), Los espíritus aliados, chamanismo y curación en los pueblos indios de Suramérica (pp. 81-154). Quito: Ediciones Ayba-yala.

Ricoeur, Paul. (2004). De la memoria y la reminiscencia. En La Memoria, la historia, el olvido (pp. 17-172). Buenos Aires: Fondo de Cultura Económica.

Sack, Robert. (1986). The meaning of territoriality. En Human territoriality: Its Theory and History (pp. 5-27). Cambridge: Cambridge University Press.

Stipek, George. (1976). Sociocultural responses to modernization among de colombians Embera (Phd thesis). State University of New York at Binghamton. New York.

Tribunal Superior, Distrito Judicial de Antioquia. Sentencia 007 de 2014. Proceso de restitución de derechos territoriales resguardo indígena Embera Katío del Alto Andágueda.

Ulloa, Astrid. (1992). Los emberá. En Geografía Humana de Colombia. Región Pacífico Tomo IX (pp. 86-116). Bogotá: Instituto Colombiano de Cultura Hispánica. 
Ulloa, Astrid; Rubio, Heidi y Campos, Claudia. (1996). Trua Wandra: estrategias para el manejo de fauna con comunidades Embera en el Parque Nacional Natural Utría, Chocó, Colombia. Bogotá: Editorial Buena Semilla.

Vasco, Luis. (1975). La comunidad indígena "Chamí" de Pueblo Rico y Mistrató. Proyecto de delimitación de un área de reserva. Bogotá: Incora.

Vasco, Luis Guillermo. (2011). Reflexiones para el desarrollo de una política pública intercultural con el pueblo Embera residente en Bogotá. En Notas sobre los Embera-Chami en Bogotá. Bogota: Corporación Burunde.

Vía Plural. (2009). Informe final. Identificación y caracterización socioeconómica, cultural y nutricional del observatorio de la situación de los niños, niñas y de las familias Embera en Bogotá. Bogotá: Instituto Colombiano de Bienestar Familiar/Vía Plural. 